\title{
Diaphragmatic Function Assessed by Bed Side Ultrasonography in Patients with Sepsis or Septic Shock Admitted to Intensive Care Unit
}

\author{
Amal Zaki ${ }^{1 *}$ (D), Helmy Hassan El Ghawaby ${ }^{1}$, Mostafa Mahmoud Mohammed Gad ${ }^{2}$, Amira Mohamed Ismail $^{1}$, Amr Shafiq Nawar $^{1}$ \\ ${ }^{1}$ Department of Critical Care, Cairo University, Kasr Alainy Hospital, Cairo, Egypt; ${ }^{2}$ Department of Radiology, Cairo University, \\ Kasr Alainy Hospital, Cairo University, Cairo, Egypt
}

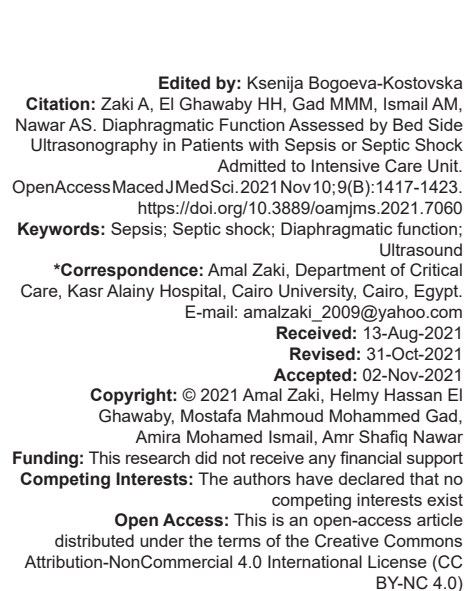

BY-NC 4.0

\begin{abstract}
BACKGROUND: Sepsis and septic shock are major problems faced the healthcare systems all over the world every year. The ultrasound (US) is a simple, non-invasive, easily accessible technique, and showed great accuracy in diaphragm assessment.

AIM: We evaluated the diaphragmatic function assessed by US in patients with sepsis and septic shock and correlated these assessments with different parameters.

MATERIALS AND METHODS: A prospective observational study carried out on 30 patients admitted to the intensive care unit (ICU) diagnosed with sepsis and/or septic shock. Both diaphragmatic excursion (DE) and thickness fraction (diaphragm thickening fraction [TDI] \%) were assessed by US on admission and every $48 \mathrm{~h}$ along the patients' ICU stay.

RESULTS: In the current study, there was a statistically significant reverse relationship between mortality and the different diaphragmatic function parameters (DE on admission, average DE, on admission TDI\%, average TDI\%). On the other hand, the DE (on admission and average) showed a statistically significant reverse relation with the need and duration of mechanical ventilation (MV) while the TDI\% showed a statistically significant reverse relation only with the duration of MV. Besides, there was a statistically significant direct relationship between successful weaning from MV and all the measured parameters.

CONCLUSION: We proposed that the diaphragmatic function parameters (DE on admission, average DE, on admission TDI\% and average TDI\%) assessed by US of septic ICU patients could be used as a predictor of the
\end{abstract} need, duration, and successful weaning from MV and also as a predictor of mortality.

\section{Introduction}

The improper host response to infection could lead to a serious condition of organs failure known as sepsis. Clinically, sepsis could be identified as a progressive increase in the sequential (Sepsisrelated) Organ Failure Assessment score $>2$ and it is accompanied by an increase in the in-hospital mortality $>10 \%$ [1]. The septic shock is the worst scenario of host response characterized by significant circulatory, cellular, and metabolic dysfunctions and associated with a higher mortality rate more than sepsis alone. Clinically, the septic shock is recognized by a requirement of vasopressor to keep the mean arterial pressure $>65 \mathrm{~mm} \mathrm{Hg}$ and serum lactate level $>2 \mathrm{mmol} / \mathrm{L}$ $(>18 \mathrm{mg} / \mathrm{dL})$ in the absence of decreased plasma volume [1]. Unsurprisingly, the occurrence of sepsis and septic shock together upsurge the in-hospital mortality rate $>40 \%$.

Nowadays, a great interest in the diaphragmatic functions has grown steadily concerning its adverse clinical effect on weaning outcomes, the duration of mechanical ventilation (MV) [2], survival, and long-term consequence in the intensive care unit (ICU) patients [3], [4]. The deployment of ultrasound (US) to assess ICU patients is strongly recommended [5] due to its portability, safety, rapidity, and easily obtained results. Concerning the assessment of the diaphragmatic functions, the US could provide many helpful data about both the structural and functional components of the diaphragm at the bedside [6], [7]. In addition, the US accuracy for diaphragm assessment seems to be the same as most other imaging techniques [8], [9], [10], [11], [12].

The diaphragmatic excursion (DE) and the diaphragm thickening fraction (TDI\%) are two sonographic parameters measured to predict the diaphragmatic functions. The DE measures the distance that the diaphragm can move during the respiratory cycle while the TDI\% [13] reflects variation in the thickness of the diaphragm during the respiratory effort and is calculated as (thickness at end-inspiration-thickness at the end-expiration)/ thickness at the end of the expiration percentage; which normally $>20 \%$ [13]. 


\section{Materials and Methods}

\section{Study population}

From June 2019 to January 2020, they study was conducted on 30 consecutive patients above 18 years admitted to the ICU diagnosed with sepsis or septic shock on admission and through their ICU stay.

\section{Patient management}

\section{Examination and diagnosis}

On admission, all the patients in the study were subjected to the following:

- $\quad$ Full history taking

- Complete clinical examination (conscious level recorded by the Glasgow Coma Scale, hemodynamics (HR, BP, temp, RR, UOP, SPO2), acute physiology and chronic health evaluation II score (APACHE II), complete neurological, chest, cardiac, and abdominal examination) Full laboratory investigation (arterial blood gases, random blood sugar, renal function test (urea and creatinine), cardiac enzymes, coagulation profile, complete blood count, blood lactate quantitative C-reactive protein (CRP), cultures and sensitivity for detecting the source of sepsis and causative organism) Imaging study (chest X-ray, ECG, Transthoracic $\mathrm{ECHO}$, and diaphragmatic US to assess the diaphragmatic functions [DE and TDI\%]).

\section{Treatment}

Meticulous management of all patients according to Surviving Sepsis Campaign: International Guidelines for Management of Sepsis and Septic Shock [14], [15].

Assessment of the diaphragmatic function: Using commercially available Samsung Medison SonoAce R3 portable US. Both excursion (with M mode using Medison CN Convex (2-8 MHz) abdominal, $\mathrm{OB} / \mathrm{Gyn}$, renal transducer), and diaphragmatic thickness fraction (with B mode using Medison Linear [5-12 MHz] $60 \mathrm{~mm}$ Small Parts, Breast, Vascular) were measured on admission and every $48 \mathrm{~h}$ along the patients' ICU stay as follows:

\section{The $D E$}

- Was assessed with M-mode US device at the bedside with a low-frequency curvilinear or phased-array transducer $(2-8 \mathrm{MHz})$ using the probe will be placed lower intercostal or subcostal between the mid-clavicular and anterior axillary lines on the right side, so that the US beam reached perpendicularly the posterior third of the right hemi diaphragm and on the left side of the diaphragm was studied from a lower intercostal or subcostal approach The diaphragm inspiratory amplitude (excursion) was measured from the M-mode sonography. The first caliper was placed at the foot of the inspiration slope on the diaphragm echoic line, and the second caliper was placed at the apex of this slope. For measurements, the amplitude of excursion was measured on the vertical axis of the tracing from the baseline to the point of the maximum height of inspiration on the graph. Several respiratory cycles were recorded, and measurements were average from three different cycles. Abnormal mobility was considered if $<1.2 \mathrm{~cm}$ in the supine position [13].

\section{The TDI\%}

Thickness assessment of the diaphragm could be obtained at the zone of apposition on an intercostal view using two-dimensional B-mode US and requires a high-frequency linear-array probe $(5-12 \mathrm{MHz})$. The transducer was positioned at the mid-axillary line at the intercostal space between the seventh and eighth ribs or the eighth and ninth ribs to obtain an ultrasonographic image in the sagittal plane. So that the US beam reached perpendicularly the posterior third of the hemi diaphragm in the supine position with an average inclination of 45 degree

- The diaphragm was identified as a three-layer structure consisting of one relatively non-echogenic muscle layer coated in two echogenic lines determined by peritoneal serosa and diaphragmatic pleura. Diaphragmatic thickness was measured at the end-inspiration and -expiration

- The change in diaphragmatic thickness $(\Delta T D I)$ during spontaneous breathing from the functional residual capacity to VT with normal value TDI\% >20\% [13] was calculated as follows:

$$
\Delta \mathrm{TDI} \%=\frac{\begin{array}{l}
\text { End }- \text { Inspiration thickness }- \\
\text { End }- \text { Expiration thickness }- \text { Expiration thickness }
\end{array} \times 100}{}
$$

- US measurements were performed three times with the best value chosen as representative of diaphragmatic thickness fraction.

\section{Statistical analysis of the data}

The statistical package STATA 13.1 (StataCorp Ltd., College Station, TX, USA) was used for analysis. 
Descriptive statistics for continuous variables presented as median (first to the third quartile). The nonparametric Wilcoxon test (Mann-Whitney) used for the comparison of continuous variables. Associations between dichotomous variables were performed by the Chi-square test or Fisher's exact test, where appropriate. The impact of sepsis on diaphragmatic function and short- or long-term mortality was assessed by Kaplan-Meyer survival function estimates. $p<0.05$ considered significant.

\section{Results}

\section{Demographic data}

Our study included 30 patients 10 of them were males $(33.3 \%)$ and 20 females $(66.7 \%)$ with a mean age of $71.87 \pm 17.42$ years (Table 1 ).

Table 1: Distribution of the studied cases according to demographic data

\begin{tabular}{lll}
\hline Total $(\mathrm{n}=30)$ & No. & $\%$ \\
\hline Sex & & \\
Male & 10 & 33.3 \\
Female & 20 & 66.7 \\
Age & & \\
$\quad$ Min.-Max. & $29.0-100.0$ & \\
Mean \pm SD. & $71.87 \pm 17.42$ & \\
\hline
\end{tabular}

\section{Diaphragmatic function parameters; $D E$} and the TDI\% on admission and along the ICU stay assessment and their correlation with mortality and APHACE II

The DE measured by $M$ mode US on admission, had a mean of $1.19 \pm 0.68 \mathrm{~cm}$ while the DE average through the whole ICU stay had a mean of $1.21 \pm 0.58 \mathrm{~cm}$. The Mean of TDI\% measured by B mode US on admission was $34.47 \pm 22.45 \%$ and its average mean was $33.27 \pm 15.37$, illustrated in Table 2 .

Table 2: Diaphragm DE and TDI\% on admission and its average of every $48 \mathrm{~h}$ along with the ICU stay

\begin{tabular}{lll}
\hline Parameter & On admission & Average along with the ICU stay \\
\hline DE & & \\
Min.-Max. & $0.16-2.70$ & $0.13-2.28$ \\
Mean \pm SD. & $1.19 \pm 0.68$ & $1.21 \pm 0.58$ \\
Median (IQR) & $1.05(0.6-1.7)$ & $1.17(0.7-1.68)$ \\
TDI\% & & \\
Min.-Max. & $5.0-84.0$ & $13.50-69.33$ \\
Mean \pm SD. & $34.47 \pm 22.45$ & $33.27 \pm 15.37$ \\
Median (IQR) & $26.50(19.0-56.0)$ & $32.20(20.67-43.1)$ \\
\hline ICU: Intensive care unit, DE: Diaphragmatic excursion, TDI\%: Diaphragm thickening fraction.
\end{tabular}

Regarding the relationship between the DE and mortality, there was a statistically significant reverse relationship between mortality and the DE on admission to ICU and average levels of DE with a p-value of $0.005^{*}$, and $0.003^{*}$, respectively. The same was found between mortality and TDI\% on admission to ICU with a p-value of $0.033^{*}$ and the average levels of TDI\% with a p-value of $0.003^{*}$ (Table 3 ).

The ROC curve (Figure 1) is showing that the APACHE II in our study had a significant relation
Table 3: Correlation diaphragmatic function (DE, TDI\%) on admission and average along the ICU stay to predict the mortality of the studied cases

\begin{tabular}{|c|c|c|c|c|}
\hline \multirow[t]{2}{*}{ Parameter } & \multicolumn{2}{|l|}{ Mortality } & \multirow[t]{2}{*}{$U$} & \multirow[t]{2}{*}{$\mathrm{p}$} \\
\hline & No $(n=15)$ & Yes $(n=15)$ & & \\
\hline \multicolumn{5}{|l|}{$\mathrm{DE}$} \\
\hline \multicolumn{5}{|l|}{ On admission } \\
\hline Min.-Max. & $0.16-2.70$ & $0.31-2.61$ & \multirow[t]{3}{*}{$46.0^{*}$} & \multirow[t]{3}{*}{$0.005^{\star}$} \\
\hline Mean \pm SD & $1.48 \pm 0.61$ & $0.90 \pm 0.63$ & & \\
\hline Median (IQR) & $1.42(1.2-1.8)$ & $0.72(0.5-1.0)$ & & \\
\hline \multicolumn{5}{|l|}{ Average } \\
\hline Min.-Max. & $0.13-2.28$ & $0.35-1.87$ & \multirow[t]{3}{*}{$41.0^{*}$} & \multirow[t]{3}{*}{$0.003^{\prime}$} \\
\hline Mean \pm SD. & $1.51 \pm 0.57$ & $0.91 \pm 0.43$ & & \\
\hline Median (IQR) & $1.53(1.2-1.9)$ & $0.84(0.5-1.2)$ & & \\
\hline \multicolumn{5}{|l|}{ TDI\% } \\
\hline \multicolumn{5}{|l|}{ On admission } \\
\hline Min.-Max. & $10.0-84.0$ & $5.0-69.0$ & \multirow[t]{3}{*}{$61.50^{*}$} & \multirow[t]{3}{*}{$0.033^{*}$} \\
\hline Mean \pm SD & $42.87 \pm 24.17$ & $26.07 \pm 17.56$ & & \\
\hline Median (IQR) & $36.0(25.0-58.5)$ & $24.0(13.5-29.5)$ & & \\
\hline \multicolumn{5}{|l|}{ Average } \\
\hline Min. Max. & $20.67-64.50$ & $13.50-69.3$ & \multirow[t]{3}{*}{$41.0^{*}$} & \multirow[t]{3}{*}{$0.003^{*}$} \\
\hline Mean \pm SD & $41.95 \pm 11.5$ & $24.59 \pm 14.0$ & & \\
\hline Median (IQR) & $42.0(34.4-46.9)$ & $22.0(15.6-25.4)$ & & \\
\hline
\end{tabular}

with mortality with $\mathrm{p}$-value $0.001^{*}$ with cutoff value $>32$ and area under the curve (AUC) $0.862^{*}$, sensitivity $80.0 \%$ and specificity $80.0 \%$. Furthermore, the different diaphragmatic functions had as significant reverse relation to mortality as the average of TDI\% was the most significant parameter to predict the mortality with the cutoff value $\leq 25.7 \%$ and AUC $0.880^{*}$, sensitivity $80.0 \%$ and specificity $93.33 \%$, followed by the average DE with the cutoff value of $\leq 1.272 \mathrm{~cm}$ and AUC was $0.818^{*}$ with sensitivity $86.67 \%$ and specificity $73.33 \%$. Furthermore, the DE and TDI\% on admission showed significant reverse relationship with mortality with AUC $\left(0.796^{*}, 0.727^{*}\right)$, respectively. However, there was no significant difference between the four parameters regarding the association with mortality so any one of them could be used as a predictor of mortality. While

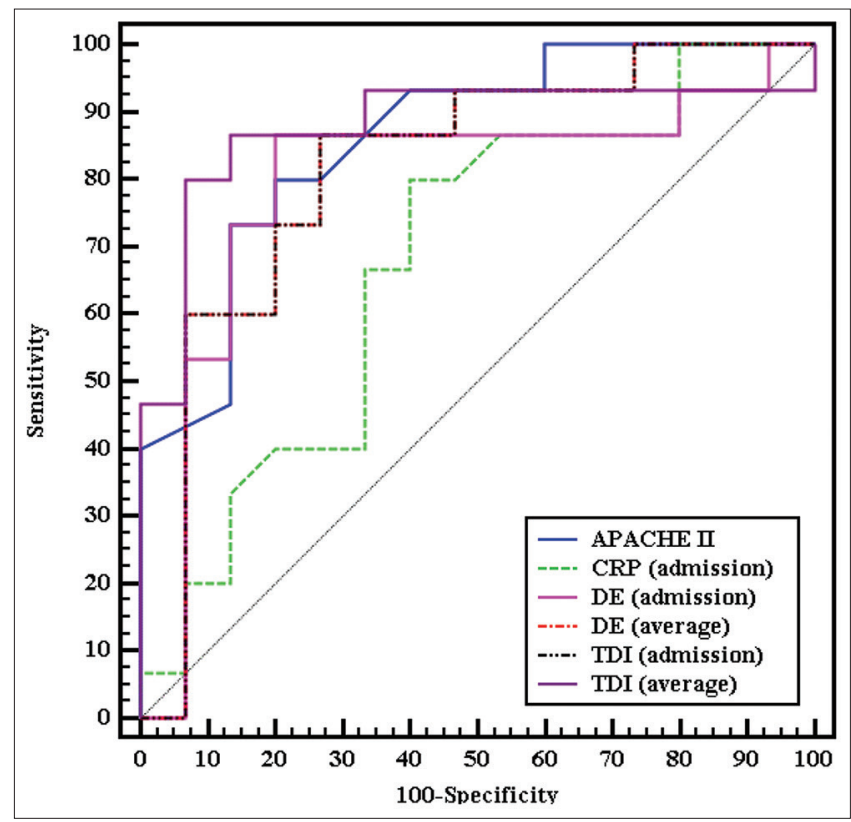

Figure 1: Receiver operating characteristic curve showing Correlation between acute physiology and chronic health evaluation II score, C-reactive protein, diaphragmatic function (Diaphragmatic excursions, Diaphragmatic Thickening Fraction) on admission and average along the intensive care unit stay to predict the mortality of the studied cases 
CRP had no significant relation with mortality with $\mathrm{p}=0.093$ and AUC 0.680 .

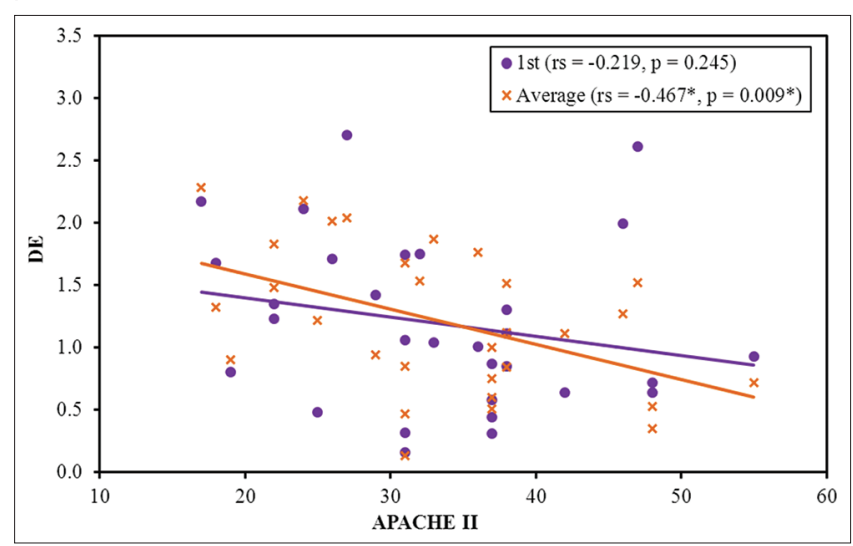

Figure 2: Correlation between Diaphragmatic excursions and the acute physiology and chronic health evaluation II score

In our study, there was statistically significant reverse relationship between APACHE $\|$ and the average of DE and TDI\% along the ICU stay with p-value $0.009^{*},<0.001^{*}$, respectively while there was no statistically significant relationship between APACHE II and DE and TDI\% on admission to ICU with p-value of $0.245,0.051$, respectively (Figures 2 and 3 ).

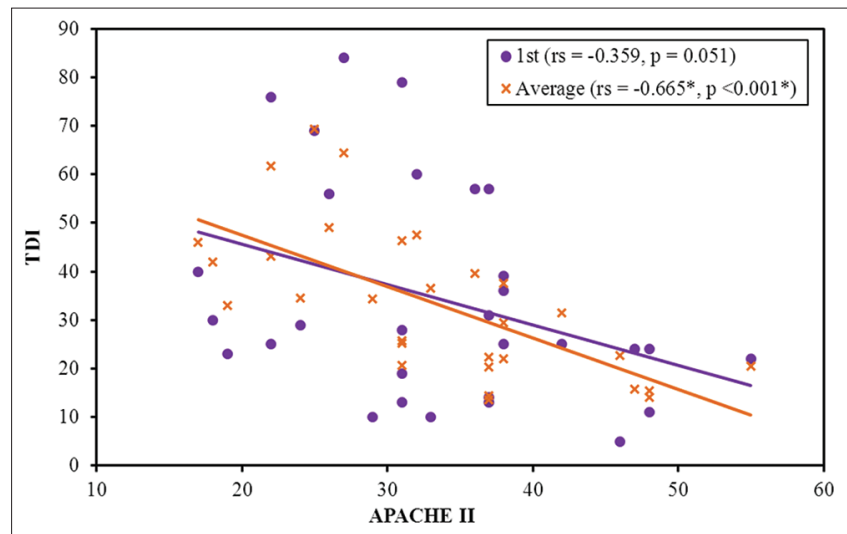

Figure 3: Correlation between Diaphragmatic Thickening Fraction and the acute physiology and chronic health evaluation II score

\section{Correlation between the different} diaphragmatic function parameters; DE and the TDI\% in association with the need of MV and prediction of weaning from MV

A statistically significant reverse relation was found between the need of MV and the DE on admission to ICU with a p-value of $0.050^{*}$, also a significant reverse relationship between the need of $\mathrm{MV}$ and the average levels of DE with a p-value of $0.031^{*}$. However, there was no statistically significant relationship between the need of MV and the TDI\% in the on admission to ICU with a p-value of 0.118 although the mechanically ventilated cases had a lower mean of $32.14 \pm 23.17 \%$. and there was no statistically significant relationship between the need of $\mathrm{MV}$ and the average levels of TDI\% with a p-value of 0.078 . Regarding the DE, there was a statistically significant reverse relationship between the duration of $\mathrm{MV}$ and the $\mathrm{DE}$ on admission with a p-value of $0.017^{*}$ and the average levels of $\mathrm{DE}$ along the ICU stay with a p-value of $0.007^{*}$ (Figures 4 and 5). In addition, there was a statistically significant reverse relationship between the duration of MV and the TDI\% on admission with a p-value of $0.041^{*}$ and the average levels of TDI\% along the ICU stay with a p-value of $0.015^{*}$ (Figures 4 and 5).

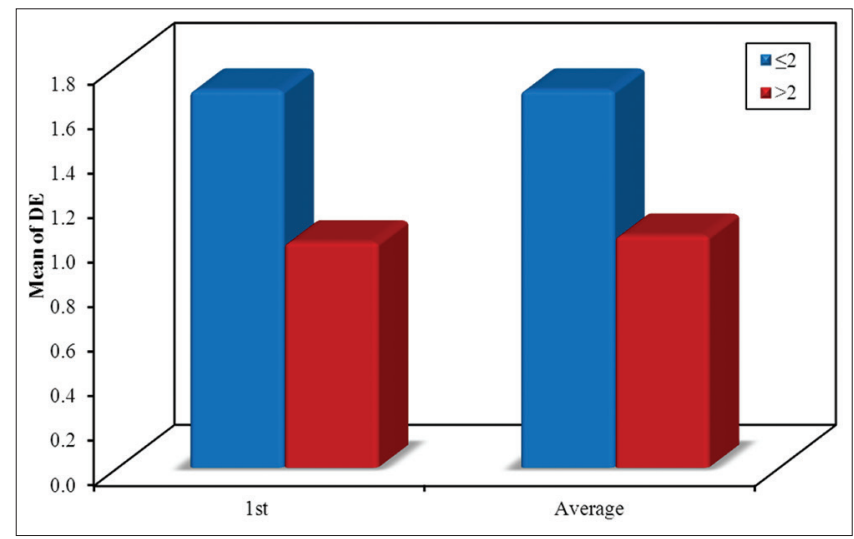

Figure 4: Correlation between Diaphragmatic excursions in association with the duration of mechanical ventilation

There was a statistically significant direct relationship between successful weaning from MV and the DE on admission to ICU with a p-value of $0.005^{*}$ and the average levels of DE along the ICU stay with a p-value of $0.002^{*}$. In addition, the TDI\% on admission to ICU had a statistically significant direct relation with MV successful weaning with a p-value of $0.033^{*}$, and the same relationship between the MV successful weaning and the average levels of TDI\% with $p$-value of $<0.001^{*}$ (Figures 6 and 7 ).

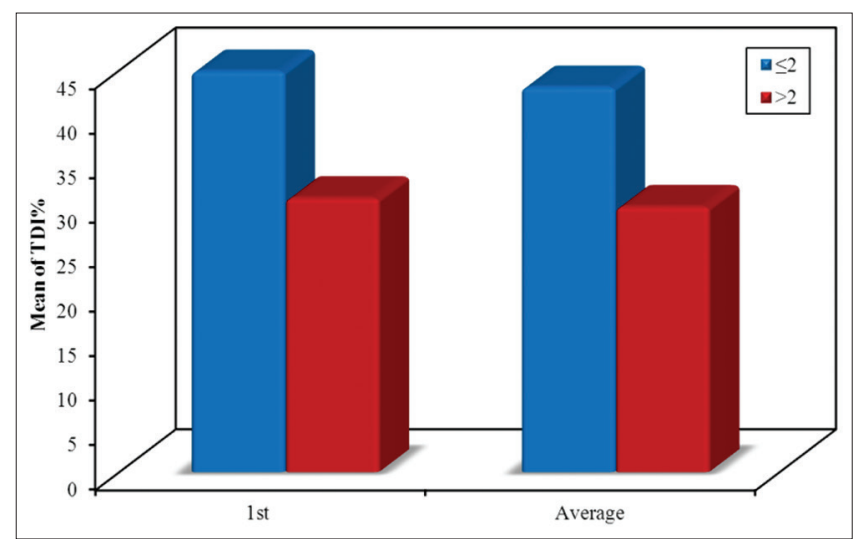

Figure 5: Correlation between Diaphragmatic Thickening Fraction in association with the duration of mechanical ventilation

The ROC curve in Figure 8 showed that the average of TDI\% was the most significant parameter to predict successful weaning from MV with the cutoff value $>25.66$ and AUC $0.848^{*}$, sensitivity $87.50 \%$ and specificity $78.57 \%$ while the TDI\% on admission showed cut off point $>24$ with sensitivity $75.0 \%$ and specificity $64.29 \%$, the DE on admission and the average DE along the ICU stay with the cutoff value of $>1.04,>0.84 \mathrm{~cm}$ and with sensitivity $87.50 \%, 87.50 \%$ and specificity $85.71 \%, 57.14 \%$, respectively. 


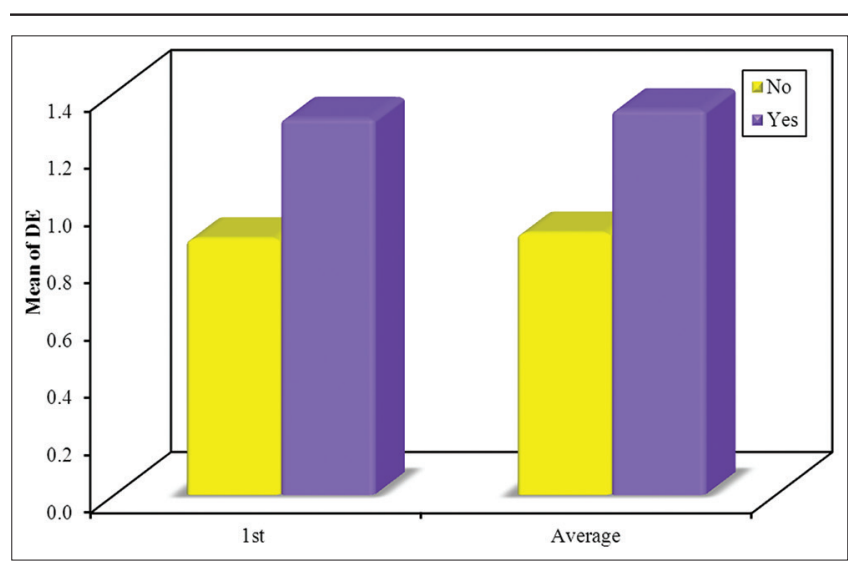

Figure 6: Correlation Diaphragmatic excursions in association with prediction of successful weaning from mechanical ventilation

\section{Discussion}

US is a safe and easy bedside imaging modality that could accurately evaluate the diaphragmatic functions in the ICU patients. In septic ICU patients, the mortality rate could be predicted by assessment of the diaphragmatic functions using US [6], [7]. Hence, this study aimed to evaluate the diaphragmatic function assessed by US in patients with sepsis and septic shock admitted to ICU along their ICU stay with correlating the diaphragmatic function assessed by US with the inflammatory marker CRP, sepsis severity and ICU length of stay, in-hospital mortality, duration of MV and successful weaning from MV.

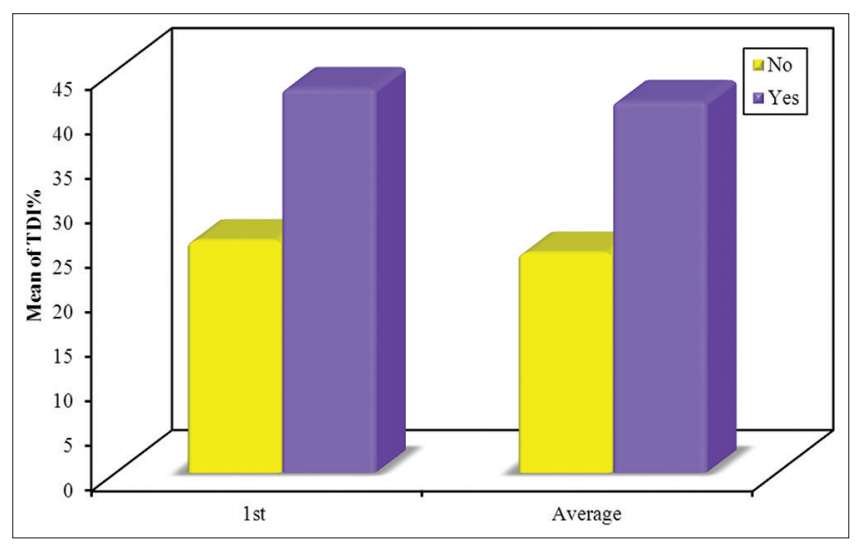

Figure 7: Correlation between the Diaphragmatic Thickening Fraction in association with prediction of successful weaning from mechanical ventilation

In our study, there was a statistically significant reverse relationship between mortality and the values of the DE and the TDI\% on admission to ICU and their average along the ICU stay. This result was consistent with Mariani et al. [2], who assessed the diaphragmatic functions in $34 \mathrm{ICU}$ patients during weaning trials using US. The US examination was performed by two blinded ultrasonographers who evaluated each hemi diaphragm during a spontaneous breathing trial. The diaphragmatic dysfunction (DD) was detected in $38 \%$ of patients on both sides with a higher ICU mortality rate in patients with DD (37\% vs. $\left.5 \%, p^{1 / 4} 0.048\right)$.
Although our study showed that the average of TDI\% with B mode was the most significant parameter to predict the mortality more than average DE by M-mode, there was no significant difference between them. That was in disagreement with Mariani et al. [2], where DE with M-mode had better reproducibility.

In an observational, prospective study, Abdelhafeez et al. [16] evaluated the role of diaphragm in the weaning outcome also with assessment of the weaning process by looking to the duration of ventilation, the time needed for weaning and the length of ICU stay, re-ventilation and the patient's final fate. The findings of the study were similar to our results that showed lower statistically significant values of all sonographic measurements in relation to mortality.

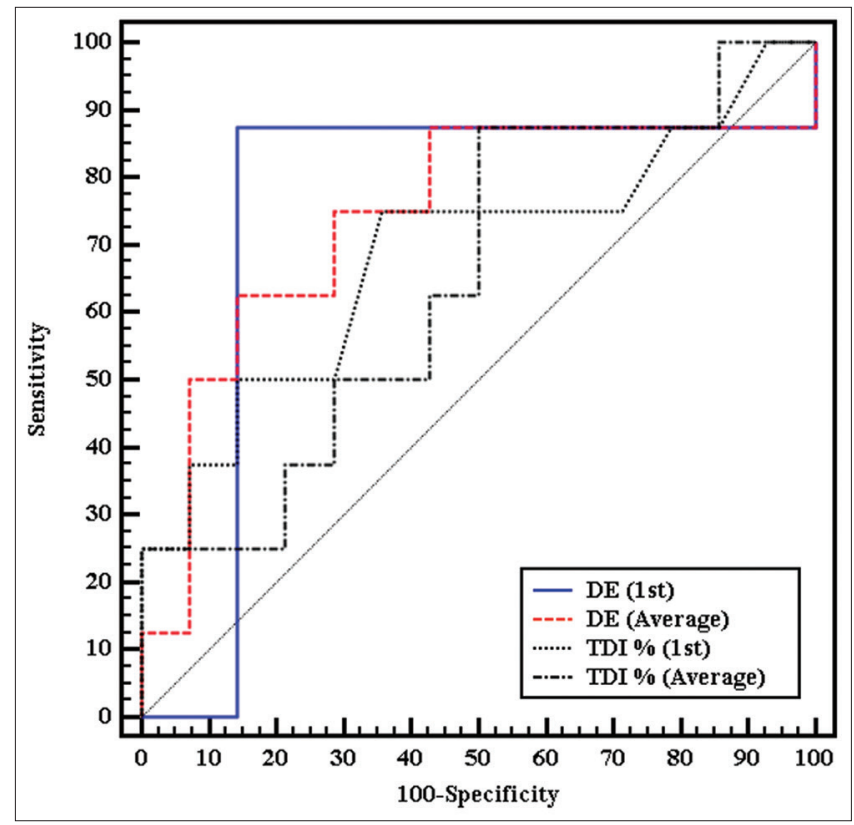

Figure 8: Receiver operating characteristic curve for different parameters to predict successful weaning from mechanical ventilation

The same was found by measuring the transdiaphragmatic twitch pressure (PdiTw) in response to bilateral magnetic stimulation of the phrenic nerves in Supinski and Callahan [17], they assessed the diaphragm strength in mechanically ventilated medical ICU patients. The study showed that the patients with severe diaphragm weakness (PdiTw $<10 \quad \mathrm{cmH} 2 \mathrm{O}$ ) had poor outcomes, with evidently high mortality (49\%) compared to patients with PdiTw $\geq 10 \mathrm{cmH} 2 \mathrm{O}$ ( $7 \%$ mortality, $p=0.022)$.

In addition, there was a statistically significant reverse relationship between APACHE II and the average of DE and TDI\% along the ICU stay. This was agreed with Demoule et al. [3], a study that concluded the $\mathrm{DD}$ is a common finding on ICU admission. If DD associated with sepsis and severe illness as high APACHE II suggested a very poor prognosis.

In our study, the DE on admission to ICU had statistically significant reverse relation with the need of MV, Also a statistically significant reverse relationship between the need of MV and the average levels of 
DE. Although, the mechanically ventilated cases had a lower mean of $32.14 \pm 23.17 \%$ while the non-ventilated patients had a mean value of $40.88 \pm 20.31 \%$ of the TDI\% on admission, however, it was not statistically significant with $p$-value of 0.118 , the same for the average levels of TDI\% along the ICU stay with p-value of 0.078. In agreement with Goligher et al. [18], who studied the diaphragmatic activity using the US in mechanically ventilated patients. They measured the diaphragm thickness TDI and thickening fraction TDI\% to detect the actual cause of diaphragmatic thickening whether the passive inflation by the ventilator or the inspiratory effort. They found a significantly lower TDI\% in ventilated patients with a p-value 0.0001 . Besides, this was consistent with, Lu et al. [19], who stated that the $\mathrm{DD}$ is earlier and more severe in mechanically ventilated patients with sepsis than the patients without sepsis.

This was in agreement with Ali and Mohamad [20]; they measured diaphragm thickness and excursion by US to predict the weaning consequences. There was a statistically significant reduction in the Mean of Diaphragmatic thickness, TDI\%, and Mean of $\mathrm{DE}$ to long duration of MV. They stated that the incidence of maximum diaphragmatic changes occurred within 3 days after MV. The cutoff values of diaphragmatic US parameters predicting successful weaning were mean Diaphragmatic thickness $>2 \mathrm{~mm}$, diaphragmatic thickness fraction $>30 \%$ and $D E>1.5 \mathrm{~cm}$.

Similar findings were found in the current study where a significant reverse relationship between the duration of MV and the DE and the TDI\% on admission to ICU and average levels through the ICU stay. In addition, a statistically significant direct relationship between successful weaning from MV and both the DE, TDI\% on admission to ICU, and with the average of DE and TDI\% through the ICU stay. In addition, the average of TDI\% along the ICU stay was the most significant parameter to predict successful weaning from MV with the cutoff value $>25.66 \%$ and AUC $0.848^{*}$, sensitivity $87.50 \%$ and specificity $78.57 \%$.

Agreed with Soliman et al. [21], where they studied the chest US to calculate the lung US (LUS) score and diaphragm US to measure TDI\% in 100 invasive ventilated patients once they shifted to Spontaneous breathing trail and aimed to assess the weaning failure from MV, It found that TDI\% can predict successful weaning with the cutoff value $\geq 29.5$ with sensitivity $88.0 \%$ and specificity $80.0 \%$ with a p-value $<0.001$ while LUS score can predict weaning failure by with cutoff value $\geq 15.5$ with sensitivity $70.0 \%$ and specificity $82.5 \%$.

In agreement with Zambon et al. [22], Ferrari et al. [23] and Eltrabili et al. [24]. The current study concluded the importance and accuracy of US to assess the diaphragmatic functions in the ICU septic patients. It could be used to predict extubation consequences, to detect respiratory failure, and to assess the atrophy in mechanically ventilated.

\section{The limitation of this study}

The small sample size that may have a negative effect on the power of our statistics. So, further research with a larger group of patients is recommended to provide more accurate results

- Another concern was that diaphragmatic US like any other US is depended on the operator, image quality, patients' position, and anatomical variation

- Besides, sepsis and septic shock have a wide range of severity and usually associated with different comorbidities which may affect the power of different muscles including the diaphragm

Finally, the inaccessibility to compare the diaphragmatic function assessed by the US to the gold standard means such as the PdiTw in response to bilateral magnetic stimulation of the phrenic nerves [3], [25]

\section{Conclusion}

The diaphragmatic function assessed by US could be used as a prognostic parameter in septic patients admitted to ICU. The different diaphragmatic function parameters (DE on admission, average DE, on admission TDI\% and average TDI\%) assessed by US could successfully assess the need, duration, and weaning from MV for ICU septic patients. In addition, diaphragmatic parameters could be used as a predictor of mortality in those patients.

\section{References}

1. Singer M, Deutschman CS, Seymour CW, Shankar-Hari M Annane D, Bauer $M$, et al. The third international consensus definitions for sepsis and septic shock (Sepsis-3). JAMA. 2016;315(8):801-10. https://doi.org/10.1001/jama.2016.0288 PMid:26903338

2. Mariani LF, Bedel J, Gros A, Lerolle N, Milojevic K, Laurent V, et al. Ultrasonography for screening and follow-up of diaphragmatic dysfunction in the ICU: A pilot study. J Intensive Care Med. 2015;31(5):338-43. https://doi.org/10.1177/0885066615583639 PMid:25979406

3. Demoule A, Jung B, Prodanovic H, Molinari N, Chanques G, Coirault $\mathrm{C}$, et al. Diaphragm dysfunction on admission to the intensive care unit. Prevalence, risk factors, and prognostic impact-a prospective study. Am J Respir Crit Care Med. 2013;188(2):213-9. https://doi.org/10.1164/ rccm.201209-1668oc

PMid:23641946

4. Hermans G, Agten A, Testelmans D, Decramer M, Gayan-Ramirez G. Increased duration of mechanical ventilation 
is associated with decreased diaphragmatic force: A prospective observational study. Critical Care. 2010;14(4):R127. https://doi. org/10.1186/cc9094

PMid:20594319

5. Mayo P, Arntfield R, Balik M, Kory P, Mathis G, Schmidt G, et al. The ICM research agenda on critical care ultrasonography. Intensive Care Med. 2017;43(9):1257-69. https://doi. org/10.1007/s00134-017-4734-z

PMid:28271320

6. Lichtenstein DA. BLUE-protocol and FALLS-protocol: Two applications of lung ultrasound in the critically ill. Chest. 2015;147(6):1659-70. https://doi.org/10.1378/chest.14-1313

PMid:26033127

7. Llamas-Alvarez AM, Tenza-Lozano EM, Latour-Perez J. Accuracy of lung ultrasonography in the diagnosis of pneumonia in adults: Systematic review and meta-analysis. Chest. 2017;151(2):374-82. https://doi.org/10.1016/j. chest.2016.10.039

PMid:27818332

8. Gerscovich EO, Cronan M, McGahan JP, Jain K, Jones CD, McDonald C. Ultrasonographic evaluation of diaphragmatic motion. J Ultrasound Med. 2001;20(6):597-604. https://doi. org/10.7863/jum.2001.20.6.597

PMid:11400933

9. de Toledo JS, Munoz R, Landsittel D, Shiderly D, Yoshida M, Komarlu $R$, et al. Diagnosis of abnormal diaphragm motion after cardiothoracic surgery: Ultrasound performed by a cardiac intensivist vs. fluoroscopy. Congenit Heart Dis. 2010;5(6):565-72. https://doi.org/10.1111/j.1747-0803.2010.00431.x PMid:21106016

10. AyoubJ, Cohendy R, PriouxJ,AhmaidiS, Bourgeois JM, DauzatM, et al. Diaphragm movement before and after cholecystectomy: A sonographic study. Anesth Analg. 2001;92(3):755-61. https:// doi.org/10.1213/00000539-200103000-00038 PMid:11226114

11. Miller SG, Brook MM, Tacy TA. Reliability of two-dimensional echocardiography in the assessment of clinically significant abnormal hemidiaphragm motion in pediatric cardiothoracic patients: Comparison with fluoroscopy. Pediatr Crit Care Med. 2006;7(5):441-4. https://doi.org/10.1097/01. pcc.0000227593.63141.36 PMid:16738495

12. Lerolle N, Diehl JL. Ultrasonographic evaluation of diaphragmatic function. Crit Care Med. 2011;39(12):2760-1. https://doi. org/10.1097/ccm.0b013e31822a55e9 PMid:22094504

13. Summerhill EM, El-Sameed YA, Glidden TJ, McCool FD. Monitoring recovery from diaphragm paralysis with ultrasound. Chest. 2008;133(3):737-43. https://doi.org/10.1378/ chest.07-2200 PMid:18198248

14. Rhodes A, Evans LE, Alhazzani W, Levy MM, Antonelli M, Ferrer R, et al. Surviving sepsis campaign: International guidelines for management of sepsis and septic shock: 2016. Crit Care Med. 2016;45(3):486-552. https://doi.org/10.1097/ ccm.0000000000000192

PMid:28098591
15. Levy MM, Evans LE, Rhodes A. The surviving sepsis campaign bundle: 2018 update. Intensive Care Med. 2018;44(6):925-8. https://doi.org/10.1007/s00134-018-5085-0 PMid:29675566

16. Abdelhafeez RM, Abumossalam AM, Arram EO, Elshafey MM Abushehata ME. Diaphragm and weaning from mechanical ventilation: Anticipation and outcome. Egypt $\mathrm{J}$ Broncol. 2019;13(4):9. https://doi.org/10.4103/ejb.ejb_13_19

17. Supinski GS, Callahan LA. Diaphragm weakness in mechanically ventilated critically ill patients. Crit Care. 2013;17(3):R120. https://doi.org/10.1186/cc12792

PMid:23786764

18. Goligher EC, Laghi F, Detsky ME, Farias P, Murray A, Brace D, et al. Measuring diaphragm thickness with ultrasound in mechanically ventilated patients: Feasibility, reproducibility and validity. Intensive Care Med. 2015;41(4):642-9. https://doi. org/10.1007/s00134-015-3687-3 PMid:25693448

19. Lu Z, Ge H, Xu L, Guo F, Zhang G, Wu Y. Alterations in diaphragmatic function assessed by ultrasonography in mechanically ventilated patients with sepsis. J Clin Ultrasound. 2018;47(4):206-11. https://doi.org/10.1002/ jcu.22690 PMid:30671990

20. Ali ER, Mohamad AM. Diaphragm ultrasound as a new functional and morphological index of outcome, prognosis and discontinuation from mechanical ventilation in critically ill patients and evaluating the possible protective indices against VIDD. Egypt J Chest Dis Tuberc. 2017;66(2):187. https://doi. org/10.1016/j.ejcdt.2016.10.006

21. Soliman SB, Ragab F, Soliman RA, Gaber A, Kamal A. Chest ultrasound in predication of weaning failure. Open Access Maced J Med Sci. 2019;7(7):1143-7. https://doi.org/10.3889/ oamjms.2019.277

PMid:31049097

22. Zambon M, Greco M, Bocchino S, Cabrini L, Beccaria PF, Zangrillo A. Assessment of diaphragmatic dysfunction in the critically ill patient with ultrasound: A systematic review. Intensive Care Med. 2017;43(1):29-38. https://doi.org/10.1007/ s00134-016-4524-z

PMid:27620292

23. Ferrari G, De Filippi G, Elia F, Panero F, Volpicelli G, Apra F. Diaphragm ultrasound as a new index of discontinuation from mechanical ventilation. Crit Ultrasound J. 2014;6(1):8. https:// doi.org/10.1186/2036-7902-6-8 PMid:24949192

24. Eltrabili HH, Hasanin AM, Soliman MS, Lotfy AM, Hamimy WI, Mukhtar AM. Evaluation of diaphragmatic ultrasound indices as predictors of successful liberation from mechanical ventilation in subjects with abdominal sepsis. Respir Care. 2019;64(5):564-9. https://doi.org/10.4187/respcare.06391 PMid:30670667

25. American Thoracic Society/European Respiratory Society. ATS/ERS Statement on respiratory muscle testing. Am J Respir Crit Care Med. 2002;166(4):518-624. https://doi.org/10.1164/ rccm.166.4.518

PMid:12186831 